\title{
Determinants Socio Economic of the use of HIV VCT dans Health Zone Kenge, RDC
}

\author{
Cush Ngonzo Luwesi ${ }^{1 *}$, Zachariah Kibanda Kidiatata ${ }^{2,3}$, Wivine Nzoko Ngnis ${ }^{2,3}$, Nadine Lufwa \\ Mposo $^{2,6}$, Jospin Kapende Kilembe ${ }^{2,4}$ and Jean Lusambu Kusa ${ }^{2,5}$ \\ ${ }^{1}$ Associate Professor, Faculty of Economics, Kwango University, Kenge, DRC
}

${ }^{2}$ Assistant, Superior Institute of Medical Techniques Marie Queen of Peace Kenge (ISTM-MRP), Kenge, RD C

${ }^{3}$ Nursing Director, Kenge Reference General Hospital, Kwango Province, DRC

${ }^{4}$ Nutritionist Supervisor, Doctors of Africa (INGO), Kin Shasa, DRC

${ }^{5}$ Supervisor, Provincial Coordination of Leprosy and Tuberculosis of Kwango, DRC

${ }^{6}$ Nurse, Community Access to Rectal Artesunate for Malaria (CARAMAL) Project, Kenge Health Zone, DRC

*Corresponding author: Cush Ngonzo Luwesi, Associate Professor, Faculty of Economics, Kwango University, Kenge, DRC

\begin{abstract}
ARTICLE INFO
Received: 幽 May 06, 2019

Published: 㓞 June 03, 2019

Citation: C N Luwesi, Zachariah Kibanda K, Wivine Nzoko N, Nadine Lufwa M, Jospin Kapende K, et al. Determinants Socio Economic of the use of HIV VCT dans Health Zone Kenge, RDC. Biomed J Sci \& Tech Res 18(4)-2019. BJSTR. MS.ID.003172.
\end{abstract}

Keywords: Aids; Counseling; Screening; Seropositive Prevalence; HIV
ABSTRACT

According to WHO (2008), HIV infection remains a major concern of public health. It Among the most is dreadful killer diseases That takes off the lives of 5,500 people daily out of 7,500 daily contamination. Most of the people living with HIV/AIDS are found in the third world and about 70\% live in Sub Saharan Africa, thus the Health Zone of Kenge can be not an exception to this dram. This study Sought to determine the utilization ratio of the Counseling and Voluntary Screening (CVS) services of HIV/AIDS while describing the factors associated with the weak use of these services, in the Health Zone of the Kenge and exploit relationships entre thesis variables. Results show that the proportion of the people having already used the CVS services in the health zone of Kenge is about 14 boxes per a thousand (14\%). This utilization ratio of the CVS services is much lower than the national average 1.5\% in 2013, 3. 1\% in 2014 and 3\% in 2015. This study as well has been found the cover age of CVS services is $22.7 \%$ and there are five CVS out of 23 health units. There was also a significant relationship ship between socio-economic and organizational factors, on one end and the utilization ratio of the CVS Health services in the area of Kenge, on the other. The himself factors included my trial stat, age, household size and the knowledge of the CVS rental, among others. Based on these results the study concluded that HIV prevalence in the Health Zone of Kenge is likely to be superior to the national average. It may be highly linked to the low pace of utilization of CVS services. There is a great need for sensitization in the field of voluntary screening and the use of condoms, the distribution of ARVs and condoms to the health units, as well as the sponsorship of sick people by the political and health authorities in Gold to fight effectively HIV/AIDS.

\section{SUMMARY}

According to WHO (2008), the HIV infection remains one of the major public health problems in the world and one of the deadliest diseases, killing more than 5,500 people every day 7500 daily contaminations. About $70 \%$ of this population lives in Third World countries and more specifically in sub-Saharan Africa; therefore, the Kenge Health Zone is no exception to this tragedy. This study sought to determine the utilization rate of Voluntary Counseling and Screening (VCT) services to describe the factors associated with the low utilization of these services in the health zone Kenge and to explore relationships between these variables. The study used the quantitative Cross-sectional survey method with correlative explanatory statements to identify the factors inherent in the rejection of VCT services on a homogeneous sample of 422 respondents. The 
results indicate that the proportion of people who previously used VCT services in the Kenge health zone in 2016 would be 14 per thousand (14\%). This utilization rate of VCT services would be lower than the national average of $1.5 \%$ in 2013, 3.1\% in 2014 and $3 \%$ in 2015 while the coverage rate for CVD services is $22.7 \%$.

In addition, there are five VCTs on a set of 23 health training courses (FOSA). Finally, there is a significant relationship between the rate of VCT use in the Kenge Health Zone and socio-economic and organizational factors, including marital status, age, household size, and knowledge of community health. where the VCT is located. Based on these results, it can be concluded that HIV prevalence is above the national average in the Kenge Health Zone. It could be closely linked to the low use of VCT services. Hence the lively appeal to politico-health authorities to support awareness raising activities on the detection and use of condoms, the distribution of condoms and ARVs, as well as the care of patients to effectively fight against HIV/AIDS.

\section{Introduction}

HIV infection is and remains one of the major public health problems in the world and one of the deadliest diseases, with higher mortality in third world countries, and more specifically in Sub-Saharan Africa around $70 \%$ of people are living with HIV (WHO, 2008). WHO (2007) [1] reported that about 29.5 million people were living with HIV/AIDS in 2001 and this figure was revised upwards to 33 million in 2007, as a result of new infections mainly from Africa Sub-Saharan Africa. According to the UNAIDS report (2005) updated by WHO (2008) [32], nearly 7500 people are infected with HIV every day and 5,500 are dying of AIDS. WHO (2015) states that the main facts related to the epidemiology of HIV indicate that this infection has already killed more than 34 million people since it was declared a global pandemic in 1985 . WHO (2017) updated the number of infections 36.7 million people, including 2 million new infections, with 1.2 million deaths from one cause or another related to HIV during the year worldwide.

Today there are more than 35 million cumulative deaths since 1985. Thus HIV/AIDS remains the pandemic of $20^{\text {th }}$ century and has negative consequences for all the sectors of development. UNAIDS (2008) adds that HIV/AIDS is pandemic in Africa and is the biggest health the continent has faced since 1983, when the first AIDS cases were reported. It is estimated that 22.5 million adults and children living with HIV, while the number of new infections among adults is estimated at 1.7 million in sub-Saharan Africa, and 1.6 million people die there. WHO (2016) adds that $40 \%$ of people with HIV (more than 14 million) do not know their status. This is an extrapolation based on the number of people tested positive for HIV who did not know it at the time of the test.

One of the reasons the pandemic continues to make its way home is certainly related to the low voluntary attendance of Voluntary Counseling and Testing (VCT) services for people with HIV/AIDS. The Public Health Agency of Canada (2010) has shown that the HIV/AIDS epidemic continues to disproportionately affect homosexual, bisexual and other men who have sex with men. WHO (2014) adds that key groups, including men who have sex with men, prisoners, injecting drug users, sex workers and transgender people, are most at risk of HIV infection because they have the least access to prevention, screening and treatment services.

Surveys in sub-Saharan Africa reveal that only $12 \%$ of men and $10 \%$ of women received counseling from Voluntary Counseling and
Testing (VCT) and / or HIV testing and received the results (Karkouri 2010) [2]. These figures indicate that the number of people who have already used VCT services would not be significant in the DRC compared to the continental and global average (MINISANTE, 2009) [3]. In its report on coverage of VCT services in the health zone of Kenge, MINISANTE (2013) reports a rate of use of VCT services of $1.53 \%$ of the general population for all health facilities (FOSA) that counts the Kwango. Nevertheless, this figure was revised upwards in 2014 (3.12\%) and down in 2015, with a rate of 3\%. However, the prevalence of HIV in Kwango was around 0.3\% in 2016. Of those infected, nearly 92\% were on ARV treatment (MINISANTE, 2016).

This study aims to answer the following questions: What is the current trend in the use of VCT services in Kenge City? What are the factors associated with the low use of these services in the DRC in general and in the Kenge Health Zone in particular? The study then set the following objectives: (i) to determine the rate of utilization of the services of (CDV) in the Kenge Health Zone from 1 to June 30, 2016; (ii) describe the factors associated with the low use of these services; and (iii) explore the relationships between these variables. The study assumes that there is a significant relationship between socio-economic, socio-cultural, and organizational factors in the utilization rate of VCT services in the Kenge Health Zone. Indeed, there is a striking gap between the progression of HIV and the dynamics of HIV research in sub-Saharan Africa, especially with respect to the factors associated with low utilization of VCT services. (Sawadogo 2006) [4]. As a result, this study could, theoretically generate important data and other assumptions that can be used to identify future solutions to the problem of low VCT utilization. In addition, by explaining the factors associated with the use of voluntary counseling and testing services, this study will help all stakeholders develop effective strategies that can encourage people to use VCT services frequently to increase coverage.

\section{Literature Paper}

According to WHO (2015), sub-Saharan Africa is the most affected region in the world, with 25.8 million cases of PLHIV in 2014, while in North Africa only 35,000 people had contracted HIV in 2007 and that the total number of people living with HIV (PLWHA) in the region would be $\$ 380,000$ (Makano, 2008). The World Bank [5] reveals that the prevalence is respectively $1.8 \%$, $2.2 \%$ and $4.7 \%$ in the Ivory Coast, in Ghana and Burkina Faso. In 
Benin, the Gambia, Guinea Conakry, Guinea Bissau, Liberia, Mali, Nigeria, Sierra Leone and Togo, population prevalence between $1.2 \%$ and $1.5 \%$, while the prevalence is between $2.8 \%$ and $6.7 \%$ depending on the ANC centers. Senegal, Niger and Cape Verde have a prevalence of less than 1\% (Lowndes et al., 2008) [6].

WHO (2015) declared 54\% of people infected with HIV know their status worldwide. Today, more than 14 million people living with HIV (40\%) do not know their status. According to WHO (2016) between 2005 and 2015, the proportion of people who knew their HIV status increased from $12 \%$ to $60 \%$ worldwide. Bateganya (2010), however, reveals that the rate of use of VCT services is low, and only about one out of every 10 eligible patients have access to VCT in developing countries. This situation is essentially due shortcomings in the availability, access and attendance VCT services (FHI 2001). The difficulty of accessing testing centers and the cost of service are among the challenges in HIV testing.

According to Burundi's EDS- 2010 report, the Ministry of Health reports that $16.7 \%$ of women and men aged 15-49 have been tested for HIV voluntarily in the last 12 months (MINISANTE, 2015). In Cameroon, 39.8\% of pregnant women received HIV testing (NFETAM, 2012) [7]. While VCT is currently recognized as an effective strategy at the heart of HIV / AIDS prevention and care, testing is at the crossroads of prevention of new infections and care of patients. MOH (2008) finally HIV seroprevalence in the DRC to at least $4.1 \%$ in the general population and $90 \%$ infection recorded in the child's art were due to the vertical transmission be $1,276,392$ PLHIV. In 2010, the HIV epidemic has given sense of stability or even decline, despite the troubled times experienced by DRC between 1996 and 2003. Furthermore, despite the high number of people living already with HIV / AIDS, it is estimated that less than $10 \%$ of these people are aware of their HIV status. Surveys in sub-Saharan Africa show that only $12 \%$ of men and $10 \%$ of women received counseling and an HIV test and received the results in the DRC (MINISANTE, 2009) [8].

\section{Materials and Methods}

\section{Description Milleti had to study}

This study conducted in the Health Area (ZS) Kenge, Kwango Provincial Health Division (DPS), As from the period 1st at 30 June 2017. Count among the ones 14 DPS Kwango, Kenge has a population of slightly more than 300. 207 inhabitants (City of Kenge, 2017) [9] divided into 28 health areas of e 28 health centers each. The province of Kwango covers a total area of 89. April 58 $\mathrm{Km}^{2}$ with an estimated density of 28 habitants / $\mathrm{Km}^{2}$ in 2014 (DPSKwango 2018). She is limited to the north by the Wamba River and the Kikongo SZ; to the south by the full Makiosi and the Kimbau ZS; in the East by the Inzia River and the Masi-Manimba SZ; to the west, the river Wamba and the Boko ZS. With such track communication the national road $N^{\circ} 1275 \mathrm{~km}$ from Kinshasa. The climate is tropical wet with two wet seasons (September-January; and March-May) and two dry seasons (May to September; January- Mars). This partly explains the presence of the woodland savannah.

The city is entirely on plateaus intersected by valleys, and sometimes, hills between the rivers Wamba in the west and Bakali in the east. The Kenge soil is sandy Karoo-Kalahari type.
Its vegetation consists essentially of grassy savannahs, woodlands and forest galleries found along the rivers. The city is connected to the rest of the country mainly by the national road $N^{\circ} 1$, KinshasaKikwit. The population of Kenge is $80 \%$ rural and agro-pastoral activities is the main source of income. Trading companies also offer Employment in the areas of commerce, small and medium enterprises, motorcycle taxis as well as teaching, health and public administration. This population essentially from the Yaka ethnic group but can be cosmopolitan in urban areas. It includes the population's ethnic and tribal Yaka Pelende, Mbala, Suku, Hungani, Kongo, N gala, Swahili and phones. Pelende tribe is more predominant in SZ.

\section{Sampling Methods and Technique Collection of Donations}

This study was primarily an explanatory cross-quantitative analysis to estimate referred to the correlational background on a health survey supported by the literature and a structured interview to identify PHA having used the service VCT pending the period of research (Amouli 2013). The study sample was probabilistic and simple random.

The size was calculated by the following formula from Fischer:

$$
n=Z^{2} * \frac{(p . q)}{d^{2}} \quad \text { [Equation 1] }
$$

Or,

$\mathrm{Z}$ is the parameter of the normal distribution at $95 \%$ confidence level (in practice $=1.96$ );

$\mathrm{p}$, the probability of success of VCT services is $50 \%$; $q=1-p$, the probability of failure of VCT services, representing the proportion of people who did not use these services, is also $50 \%$; $d$, the degree of accuracy of the estimate, is practice $5 \%$. In these circumstances, the size of the sample not Is equal to 384 people; knowing that there may be no answers, we thought to increase the size of our sample by $10 \%$ which makes us a total of 422 people to interview. $\mathrm{C}$ and sample were distributed proportionately in the health areas according to the weight of their respective populations. A pre-survey had been carried out to identify in advance the problems that might arise during the investigation phase itself. Data collection was done at VCT structures of rural health zone of Kenge, especially between Misele health, Mukila Barriere and in the province of Kwango during the period from 1 to 30 in 2017 . The enquêt century were made on appointment, previously obtained from the responsible structures targeted before or scheduled interview.

Selection Criteria: The study retained in its sample subjects fulfilling the following conditions:

a) reside in one of the areas of the Zone of Santé Kenge;

b) have been seen or screened positive HIV during the study period or before it;

c) be aware of the existence of VCT are structures in the area of Santé.

Criteria for Exclusion: A person who has deliberately refused to participate in the study or were absent during the investigations was supposed to be excluded from the sample. 


\section{Technical Analysis Data}

The analyzes were mainly based on descriptive and inferential statistics. The data has been tabulated to facilitate the calculation of frequencies. The trends were identified for Basic Equation 2:

$$
\begin{aligned}
& \text { Or, } \\
& \mathrm{f}=\text { Relative frequency } \\
& \mathrm{F}_{\mathrm{o}}=\text { Frequency observed } \\
& \mathrm{FA}=\text { Expected frequency }
\end{aligned}
$$$$
f=\frac{F_{O}}{F A} * 100 \quad \text { [Equation 2 }
$$

The chi-square test ( $\mathrm{Chi}^{2}$ or $\square^{2}$ ) was used for checking the links between the actual used VCT e t socioeconomic and organizational factors associated with its used services. This head inferential analysis at allowed to test the hypothesis null e according to which there was no relation the expected distribution of the used VCT (E) and observed that these suspected socioeconomic factors explained this state of using (0). Thus, the century hypotheses hereinafter been testing:

H0: $E \neq 0$, there is a difference significative rent distribution of $\mathrm{E}$ and $\mathrm{O}$

$\mathrm{H} 1: \mathrm{E}=0$, there are not significant difference between the $\mathrm{E}$ and $\mathrm{W}$ of distributions

From an analytical point of view, has STATISTICS e chi-square (chi ${ }^{2}$ or $\square^{2}$ ) is represented by the following formula (Equation 3):

$\chi_{d d l ; p}^{2}=\sum \frac{\left(E_{j}-O_{i}\right)^{2}}{O_{i}} \quad$ [Equation 3]

Where,
$\mathrm{E}_{\mathrm{i}}$, the ith EFFECT if expected used at VCT

$O_{j}$, the jth observed effective the distribution alleged socioeconomic factors explain the used VCT

ddl, the degree of freedom (equal to nk)

$n$, the total number of the sample

$\mathrm{k}$, the number of estimated parameters (equal to the number of factors)

$\mathrm{p}$, the signification rate (equal to the probability of failure of Ho)

$\mathrm{L}$ e of statistical chi-square $\left(\mathrm{chi}^{2}\right)$ was tested significance level of $5 \%$ ( $p=0.05$ ) using the SOFTWARE computer SPSS 1.0 and 2 MS Excel 2010.

\section{Results of the Analysis \\ Proportion of use of CDV Services}

Figure 1 shown the male patients represented $50.2 \%$ of the sample against $49.8 \%$ female. This predominance explained by many men make that accordant has the importance to their status that most women; they are therefore inclined to get tested to know it. But these results are not conclusive when we look at the spatial distribution of respondents. They are influenced by the large enrollment of men (53.1\%) to AS Barriere whose effect if total respondents were 211 on effect if total of 422 (see Table 1). Otherwise, AS Mukila, men and women to be screened represented Exe quo 50\%, while the AS. Misele proportion Women (53.1\%) was higher than that of men $(46.8 \%)$.

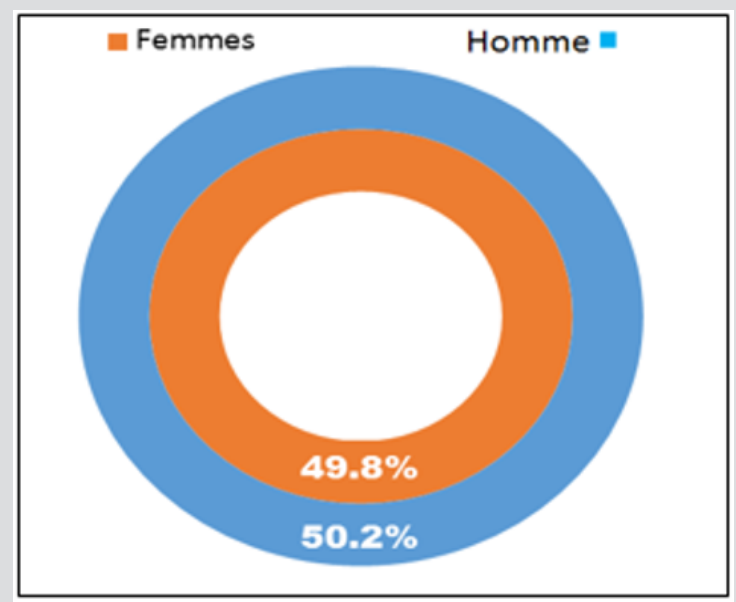

Figure 1: Sexual distribution of the people surveyed (Authors, 2017).

Table 1: Distribution of respondents according urss age bracket.

\begin{tabular}{|c|c|c|c|c|c|c|c|c|}
\hline \multirow{2}{*}{$\begin{array}{c}\text { Age range } \\
\text { (per year) }\end{array}$} & \multicolumn{2}{|c|}{ AS Barriere } & \multicolumn{2}{c|}{ AS Misele } & \multicolumn{2}{c|}{ AS Mukila } & \multicolumn{2}{c|}{ Total } \\
\cline { 2 - 9 } & Effective & Percent (\%) & Effective & Percent (\%) & Effective & Percent (\%) & Effective & Percent (\%) \\
\hline $15-20$ & 59 & 28 & 33 & 19.3 & 4 & 10 & 96 & 22,7 \\
\hline $21-25$ & 41 & 19.4 & 33 & 19.3 & 11 & 27.5 & 85 & 20,1 \\
\hline $26-30$ & 25 & 11.8 & 23 & 13.5 & 4 & 10 & 52 & 12.3 \\
\hline $31-35$ & 27 & 12.8 & 28 & 16.4 & 9 & 22.5 & 64 & 15.2 \\
\hline
\end{tabular}




\begin{tabular}{|c|c|c|c|c|c|c|c|c|}
\hline $36-40$ & 19 & 9 & 18 & 10.5 & 5 & 12.5 & 42 \\
\hline $41-45$ & 40 & 19 & 36 & 21 & 7 & 17.5 & 83 \\
\hline Total & 211 & 100 & 171 & 100 & 40 & 100 & 422 \\
\hline
\end{tabular}

Note: Source Enquêtes on land (Authors, 2017)

As for the age group, it emerges from this table that the slice of $15-20$ 's eta year it most represented (with $22.7 \%$ ), followed by that of 21-25 years (with 20.1\%), that of 41-45 years (with 19.7\%), that of 31-35 years (with 15.2\%), 26-30 years (with 12.3\%), and finally that of 36-40 years (with 10\%). The important representation of minor and major youth can be explained by made at this age of life has, youth lead a life without control, thus face the risk of reaction contaminated with HIV. Moreover, they are exposed to IEUX relative information voluntary testing and are prone to be tested for know their serological status. In addition, the distribution of the respondents the marital status (Table 2) confirms that singles, which are consents the risk of HIV infection represent more than half of a population surveyed (51.2\%), followed by $(42.4 \%)$. The other categories were not recorded proportions signiatives, including $(3.8 \%)$ of the ivorcés $(1.2 \%)$, the files- mothers $(0.9 \%)$ and people living in free union $(0.5 \%)$.

Table 2: Distribution of respondents according to their marital status.

\begin{tabular}{|c|c|c|}
\hline \multirow{2}{*}{ Marital status } & \multicolumn{2}{|c|}{ Surveyed population } \\
\cline { 2 - 3 } & Effective & Percent (\%) \\
\hline Married & 179 & 42.4 \\
\hline Single & 216 & 51.2 \\
\hline Widowed & 16 & 3.8 \\
\hline Divorced & 5 & 1.2 \\
\hline free Union & 2 & 0.5 \\
\hline Daughter-mother & 4 & 0.9 \\
\hline Total & 422 & 100 \\
\hline
\end{tabular}

Note: Source: Field surveys (Authors, 2017)

Table 3: Size of household are surveyed.

\begin{tabular}{|c|c|c|}
\hline Household size & \multicolumn{2}{|c|}{ Surveyed population } \\
\hline (per capita) & Effective & Percent (\%) \\
\hline 2-Jan & 30 & 7.1 \\
\hline 4-Mar & 66 & 15.7 \\
\hline 6-May & 142 & 33.6 \\
\hline 7 and more & 184 & 43.6 \\
\hline Total & 422 & 100 \\
\hline
\end{tabular}

Note: Source: Field surveys (Authors, 2017)

It follows from Table 3 that the miles shady typical African art those whose household size exceeds 4 people, representing $77.2 \%$ of the total number of respondents. Indeed, 184 of 422 candidates come from homemaker has seats with more than 6 people e (se t 43.6\%), and 142 people come from Men Ages whose size is 5-6 people $(33,6 \%)$. The other households represent respectively 15.7 $\%$ (those of 3-4 people) and 7.1\% (those whose size is 1 to 2 people). As of emerges Table 4 that 205 out of 422 respondents $(48,6 \%)$ had achieved a level of primary s studies, 99 (23.5\%) has just reached having the primary level, and 106 (i.e. 2.5, 1\%) having started but not completed their secondary education. Moreover, among the 87 ENQUIRIES (i.e. 20.6\%) have completed their secondary education, but only 53 respondents $(12.6 \%)$ were of the upper university.

Table 4: Level of study of respondents.

\begin{tabular}{|c|c|c|}
\hline \multirow{2}{*}{ Level of study } & \multicolumn{2}{|c|}{ Surveyed population } \\
\cline { 2 - 3 } & Effective & Percent (\%) \\
\hline No level & 77 & 18.2 \\
\hline Primary & 99 & 23.5 \\
\hline Secondary unfinished & 106 & 25.1 \\
\hline Secondary completed & 87 & 20.6 \\
\hline Superior / Academic & 53 & 12.6 \\
\hline Total & 422 & 100 \\
\hline
\end{tabular}

Note: Source: Field surveys (Authors, 2017).

Table 5: Reason given by the respondents for not having been tested.

\begin{tabular}{|c|c|c|}
\hline \multirow{2}{*}{ Reason not to have been tested } & \multicolumn{2}{|c|}{ Surveyed population } \\
\cline { 2 - 3 } & Effective & Percentage \\
\hline Reason not declared & 184 & 43.6 \\
\hline Having never been advised & 41 & 17.2 \\
\hline Not Believing to Have HIV Infection & 138 & 58 \\
\hline Afraid to die if the test is positive & 47 & 19.7 \\
\hline Distance from the CDV & 2 & 0.8 \\
\hline No VCT in the residential area & 1 & 0.4 \\
\hline $\begin{array}{c}\text { Fear divulguer status by lack of } \\
\text { confidentiality by the provider }\end{array}$ & 9 & 3.8 \\
\hline Total & 422 & 100 \\
\hline
\end{tabular}

Note: Source: Field surveys (Authors, 2017)

The importance of primary and secondary unfinished be explained by the lack of financial means and early marriage. It is the category respondents that lasts raining exposed to the risk of contraction of HIV / AIDS. Finally, in order to provide the future well-being, certain strive must last until university level have completed their high school, although they will not necessarily work After their high school. $\mathrm{C}$ and low level of education is also reflected in the raisons advanced by respondents for not been tested (Table 5) and the knowledge of the Screening Centers Voluntary (VCT) of HIV / AIDS are taken by (Table 6 and Figure 2). From Table 5, at 422 enters $43,6 \%$ (or 184 people) saw no valid reason to get tested or Declares érologique their state; only 238 subjects were given a reason they deemed valid not for sector. Among the 238 subjects, 138 do not have covalent HIV infection (58\%) and therefore it does not important to get tested. Another category composed of 47 candidates (19.7\%) did not know the results for fear of suffering the more in case of positive result, $17.2 \%$ (41 per PERSONS) could not be tested because they valiant never been well advised. Fear of 
lack of professionalism or confidentiality of the service by screening services was cited by 9 people (or 3.8\%) as a reason for refusal $u$ test, and a very small proportion respectively 0.8 and $0.4 \%$ could be tested either for reason of remoteness or lack of VCT in the radius of the residence.

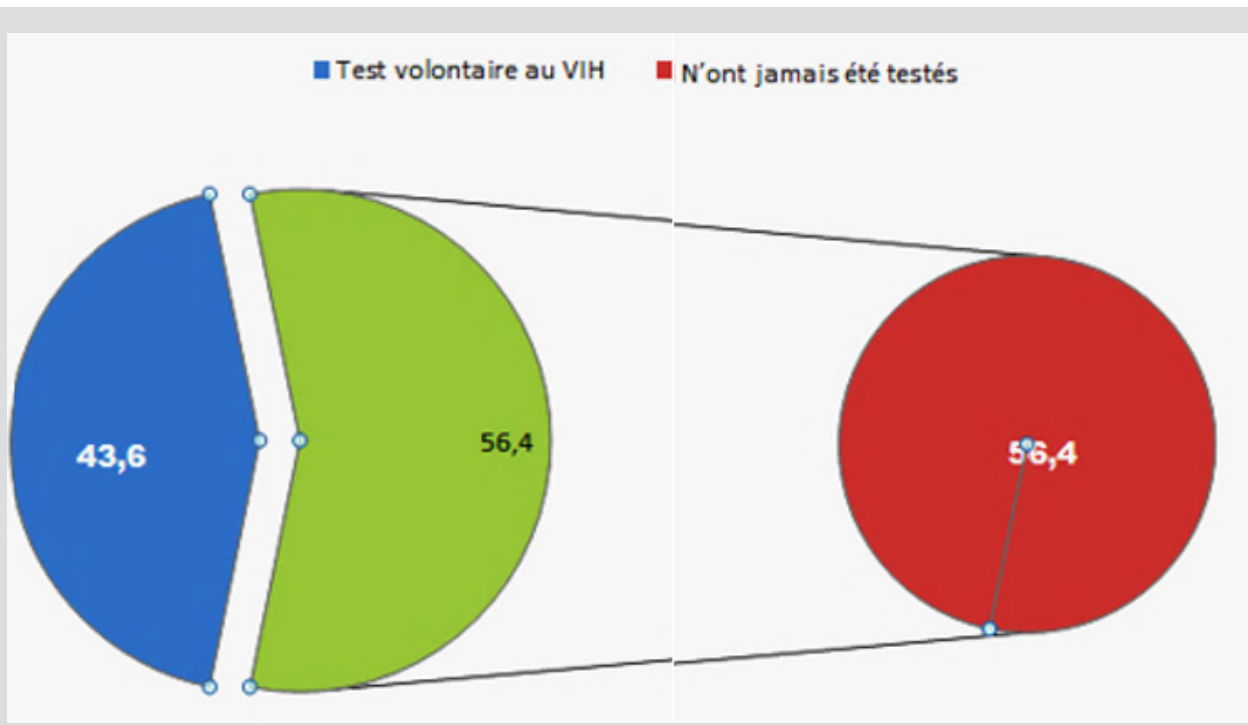

Figure 2: Proportion of respondents who have had a voluntary HIV test.

Table 6: Reason given by the respondents for not having been tested.

\begin{tabular}{|c|c|c|}
\hline \multirow{2}{*}{ Variables } & \multicolumn{2}{|c|}{ Surveyed population } \\
\cline { 2 - 3 } & Effective & Percent (\%) \\
\hline HGR & 123 & 66.8 \\
\hline CS & 61 & 33.2 \\
\hline $\begin{array}{c}\text { I do not know a single } \\
\text { CDV }\end{array}$ & 238 & 56.4 \\
\hline Total & 422 & 100 \\
\hline
\end{tabular}

Source: Enquêtes on land (Authors, 2017).

Table 7: Motivation of the respondents to make you feel at the CDV.

\begin{tabular}{|c|c|c|}
\hline \multirow{2}{*}{$\begin{array}{c}\text { Motivational ion } \\
\text { Screening }\end{array}$} & \multicolumn{2}{|c|}{ Surveyed population } \\
\cline { 2 - 3 } & Effective & Percentage \\
\hline Personal Conviction & 60 & 32,6 \\
\hline $\begin{array}{c}\text { C onus of care } \\
\text { providers }\end{array}$ & 51 & 27,7 \\
\hline $\begin{array}{c}\text { Call for blood } \\
\text { donation }\end{array}$ & 38 & 20,7 \\
\hline $\begin{array}{c}\text { Caseil of a religious } \\
\text { leader }\end{array}$ & 16 & 8,7 \\
\hline $\begin{array}{c}\text { Prenuptial } \\
\text { examination }\end{array}$ & 14 & 7,6 \\
\hline Service obligation & 5 & 2.7 \\
\hline Total & 184 & 100 \\
\hline
\end{tabular}

Note: Source: Field surveys (Authors, 2017)

Table 7 shows that by mithes 184 candidates tested, $32.6 \%$ were personal conviction (so it 60 cases), $27.7 \%$ following the provider's advice care (51 cases), $20.7 \%$ in an appellation of blood donation (38 cases), 8.7\% suite the council for religious (or 16 cases), $7.6 \%$ in the occasion a premarital examination (i.e. 14 cases), and $2.7 \%$ were obligated by their employees ( 5 cases). In addition, $61.4 \%$ of the 184 people tested (113 cases) returned for their test results to the VCT, while $38.6 \%$ (or 71 candidates) never returned, for various reasons. Among them, $57.4 \%$ said they were afraid of positive results; $29.4 \%$ were re-tensioned not received an appointment farm on the part of providers are; $2.9 \%$ of no return was justified by the delay in the delivery of results are; $10.3 \%$ Prevention (Table 8).

Table 8: Reasons for $\mathrm{n}$ e $\mathrm{t}$ re not returned looking for the results.

\begin{tabular}{|c|c|c|}
\hline \multirow{2}{*}{ Advanced reason } & \multicolumn{2}{|c|}{ Surveyed population } \\
\cline { 2 - 3 } & Effective & Percent (\%) \\
\hline $\begin{array}{c}\text { Peur of a positive } \\
\text { result }\end{array}$ & 41 & 57,4 \\
\hline No firm appointments & 21 & 29,4 \\
\hline Delayed results & 2 & 2,9 \\
\hline E spitting & 7 & 10,3 \\
\hline Total & 71 & 100 \\
\hline
\end{tabular}

Note: Source: Field surveys (Authors, 2017)

These socio factors and environment play a significant role in the spread of HIV infection in the Kenge Santé Zone. But the socioeconomic factors are none the less. The Table $9 \& 10$ respectively have the occupations careers and income level charactéristique the population enquêtée. Table 9 shows that a total of 140 applicants were unemployed (33.3\%) and 96 were freelancers or traders (22.7\%). Only 90 were paid private sector workers $(21.3 \%)$ and 43 paid in the public sector $(10.2 \%)$. The 53 remaining were posing for "resourceful" small busy shopping or other employees released (silo 12.5\%). This predominance of professions liberal and sector private in the sample s explained by job scarcities in s structures state Public Sector in the Province Kwango. As for the monthly income, the e Table 10 made status of ' unlevel average pay as 
low scales wage in the DRC, so its amount is 50 \$ US. Indeed, 236 respondents in 422 (55.9\%) were living of US \$ 2 per day poverty line while 167 from among themselves (i.e. 39.6\%) BC has u $n$ income level medium dice passing US $\$ 2$ but loweréd laughing at US $\$ 5$ a day.

Table 9: Category s socio-professional s of respondents.

\begin{tabular}{|c|c|c|}
\hline \multirow{2}{*}{ Occupational Occupation } & \multicolumn{2}{|c|}{ Surveyed population } \\
\cline { 2 - 3 } & Effective & Percentage \\
\hline Paid work public sector & 43 & 10.2 \\
\hline Paid work private sector & 90 & 21.3 \\
\hline Jobs i ndépendant or trade & 96 & 22.7 \\
\hline Retailing and ther s job s released ows & 53 & 12.5 \\
\hline Unemployed & 140 & 33.3 \\
\hline Total & 422 & 100 \\
\hline
\end{tabular}

Note: Source: Field surveys (Authors, 2017)

Table 10: Distribution of respondents according our income level.

\begin{tabular}{|c|c|c|}
\hline Monthly income & \multicolumn{2}{|c|}{ Surveyed population } \\
\hline (in US \$) & Effective & Percentage \\
\hline Poor (Less than 5 0) & 236 & 55.9 \\
\hline Low (5 0-1 50) & 167 & 39.6 \\
\hline Medium (151-3 00) & 13 & 3.1 \\
\hline High (More than 3 00) & 6 & 1.4 \\
\hline Total & 422 & 100 \\
\hline
\end{tabular}

Note: Source: Field Investigations (Authors, 2017)
The middle class was higher represented by $3.1 \%$ of respondents (13 out of 422 candidates screened) while the class average not greater than e é was represented by 6 individuals of 422 (or 1, $4 \%$ ). Its level of income household predominantly was out denoting indeed the socioeconomic conditions precarious prevailing in DRC in general and in Kwango Province, in particular. They thus have a significant influence on the spread of HIV infection in the Kenge Santé Zone.

\section{Factors Associated to Using the Services CDV}

Looking back on the possibility of association between socio economic study above it and using services of GTC, the analysis of the test Chi Square has perm is decorroborate fait these factors have a significant influence on the spread of HIV infection in the Kenge Health Zone. The Table 11 indique that only the marital, go household, Age ranch and knowledge of CDV can aptly explain the motivation of respondents to be fairer TROUBLE- voluntary lying. Indeed, the test Chi Square was rejected at 99\% confidence level the null hypothesis ( $\mathrm{Ho}$ ) according to which there is no relationship close between service utilization of VCT and these characteristics socio econonomic, with the exception perhaps of the household, where the Ho was rejected at $90 \%$ confidence level $\left(\mathrm{Khi}^{2}=0.377\right.$; $\mathrm{dd} 1=15 ; \mathrm{p}=0,09$ 7). Thus, there were significant positive relationships between marital status and use of VCT services (Khi ${ }^{2}$ $=17,794$, dof $=5 ; \mathrm{p}=0.003)$; the age and use of services CDV $\left(\mathrm{Khi}^{2}\right.$ $=78.129 ; \mathrm{df}=38 ; \mathrm{p}=0.000)$; the $\mathrm{c}$ nowledge VCT e $\mathrm{t}$ using the services of e VCT $\left(\mathrm{Khi}^{2}=116.44 ; \mathrm{dd} 1=1 ; \mathrm{p}=0.000\right)$; and finally, between the t go household using the services of $\operatorname{CDV}\left(\mathrm{Khi}^{2}=0.377\right.$ ; df = 15; $\mathrm{p}=0,097$ ).

Table 11: A ODCS i was tion between art socioeconomic variables and utilization department 's screening of V IH to Kenge.

\begin{tabular}{|c|c|c|c|c|}
\hline Variable & Khi $^{\mathbf{2}}$ & dOF & $\mathbf{p ~} \leq$ & Decision \\
\hline S exe & 0.377 & 1 & 0.540 & Acceptance Ho \\
\hline Marital status & 17,794 & 5 & 0,003 & Ho Rejection (99\%) \\
\hline Household size & 22,441 & 15 & 0.097 & Ho Rejection (90\%) \\
\hline age range & 78,129 & 38 & 0,000 & Ho Rejection (99\%) \\
\hline level of studies & 5,796 & 4 & 0.215 & Acceptance Ho \\
\hline $\begin{array}{c}\text { Knowledge of u CDV which is voluntary } \\
\text { testing done }\end{array}$ & 116.44 & 1 & 0,000 & Acceptance Ho \\
\hline Attitude to VCT & 2,122 & 1 & 0,145 & Acceptance Ho \\
\hline Occupational Occupation & 8,512 & 5 & 0,130 & Acceptance Ho \\
\hline Monthly income of u household & 0,650 & 3 & 0.885 & \\
\hline
\end{tabular}

Note: Source: Field Investigations (Authors, 2017)

The test Chi Square $\mathrm{n}$ 'is not a perm to establish a significant relationship s between the use of this services and sex, household size, $\mathrm{n}$ level studies, has attitude compared to CDV, professional occupation and household's monthly revenue respondents in our sample. Nevertheless, the influence of these factors on the spread of HIV in the Kenge Health Zone cannot be dismissed. Elle is probably Depending on the evolution of $\mathrm{E}$ binds social and environment to the Health Zone.

\section{Discussion of Results}

The results on the sociodemographic characteristics showed that the male (nearly 51\%), young majors and Mineurs (aged between 15 and 45 years), the single (51.2\%) and married (or 42 , $4 \%$ ) not predominated the study sample. But the participation rate of mother- daughters and people living in a free union was low. rate representativity (entire $0.5 \%$ and $0.9 \%$ ). These results are consistent with them Zigani (2004) and Tulizana (2010) in their study related the factors limiting the use of services of CDV. Zigani (2004) found that small traders of sex male working in the sector informal and having accepted the Board of VCT representant close to an $63 \%$ (as against $37 \%$ of participation female) in the town of Ouaga dougou. However, Tulizana (2010) has found participation rates low for girls- mothers and people living in free Union in its Chantil the one. 
Acting in household size, the results of our study have shown that rained s $75 \%$ of subjects' interreges underpins not from the larger families African typical of at least 6 per tones; very few among them belonged to a household least 2 persons. Furthermore, over $68 \%$ of respondents had never have their secondary education and were from the professions libera it's not paid and paid private sector has income in daily amounts of US \$2. These reasons economic and social's, are come taken poverty and the weddings early can be decisive in the transmission of HIV infection in Kenge Health Zone. In a study chronological systématique on progression HIV / AIDS in that Sub-Sahara Africa, Hargreaves et al. [10] have associated e risk of contracting HIV / AIDS to u n low level of education. Fassin (1992) and Fainzang $(2003 ; 2006)$ went further by saying that are people with education very there tend to motivate contraction virus by "the time fixed by God" or purely and simply "Good" because they say that divine union that of be infected by the HIV/ AIDS. " This sometimes makes it difficult the relations between PHAs and providers of self, begotte and " inhospitable medicine "in Africa (Côte d'Ivoire and Sardan, 2000).

Interviews had in the zone of sante on the perception of HIV reinforce these arguments. Indeed, $35.1 \%$ of interviewed affirmed not have knowledge of HIV transmission modes, and $46.2 \%$ had perceive HIV as a chronic disease incurable. Moreover, $38.4 \%$ have said they consider as a disease of love, $15.2 \%$ said that everyone is at risk of being infectéd with HIV and $0.2 \%$ very small proportion have thought that it is an AGISS environment.

Kawadogo (2007) confirmed as insufficient knowledge of the ways of HIV transmission appears to be a limiting factor for the use of VCT services in the health district of Kaya (DSK), Burkina Faso. Nevertheless, most respondents, between $70 \%$ to $99 \%$, have recognized the sexual transmission as a channel very transmission HIV / AIDS and the use of condoms and the Prevention of Mother to Child Transmission (PMTCT) as a prevention mode par excellence (Zigani, 2004). In a study of Ugandan adolescents, Bohmer et al. (1997) have intercepted that the knowledge and localization services VCT stay in to arriersto attendance these services. Thus, very little among our Interviews were reconnect that the early detection of HIV was a strategy of prevention against HIV infection (or $3 \%$ ), while $43.6 \%$ have been reconnected by the place where one is screening Volunteer.

Zigani (2007) has hasted that if $39 \%$ of respondents louse haven't know the establishment where will realize the test of screening voluntary, only $25 \% \mathrm{p}$ o uv 'veent really dire it allows was of the s protect against the HIV infection / AIDS or could the aid first to start treatment on time. In our study only $43.6 \%$ of respondents living in Kenge Health Zone reported having been screened volunteer against $12 \%$ in the DRC, $16.7 \%$ in Burundi, and $39.8 \%$ in Cameroon that the have been (PNLS, 2009, NFETAM, 2012, MINISANTE, 2015). Zigani [45] dreamed l was that a majority of e s persons in petty trading refusal 've ent to know their status serology of HIV $\mathrm{p}$ ar fear of êT $r$ e reject ed by the company, while Baggaley et al. [11], found that e the majority of young Zambia ns (or $92.7 \%$ ) refusal have e nt to be test first, even free, for fear of e know to be HIV positive and to die.
And in our sample, $58 \%$ of e $\mathrm{n}$ that ê sides had found no reason good to get tested because they croya ian $t$ does not have HIV infection while $19.7 \%$ were afraid to die if positive results, and 17.2 $\%$ said No ' av o ir never been advised to get tested. The e lack of confidentiality of per $t$ of service s, the remoteness and lack of VCT VCT within the radius of the residence were minor reasons of $u$ refusal to be test first. Thus $38.6 \%$ of our respondents $n$ e are never returned seek ur s results without any reason while $57.4 \%$ were of eClare not be back born of fear of rece see the results positive. All this s results corroborate with those of Ouédraogo et al. [12], Msellati et al. (2001) and Cartoux et al. (1998). almost Few of years all are near to be voluntarily tested against HIV / AIDS and returned for the ur r UTCOME test HIV or less of in informing their partners. Indeed, Ouédraogo et al. [12] disa ie nt than whether the use of voluntary HIV testing e t has remained low, it is because people avaie nt fear negative reactions from those around them. The existence of HIVrelated stigma is a factor that impedes the use of VCT services in the Kaya Health District (KDS). Msellati et al. (2001) and Cartoux et al. (1998) not observed that fear pervaded most pregnant women that and $\mathrm{i} l$ had to accept $\mathrm{r}$ to be voluntarily $\mathrm{t}$ is first order to know if they and their babies were infected with HIV. In fact, m ê me when they accepted screening, they only haven't returned more to take their outcome.

As for the circumstance s that led to screening voluntary, the majority of people in the Health Zone Kenge was persuaded by authorities or health, social or Religious her (almost $70 \%$ ) in to an e prestat public or ion private, including of s care, call Donation of blood and a premarital examination. Only $32.6 \%$ were motivated by the belief s personal s. Thus, the art communication channels officials find their purpose entant networks that promote behavior change for $\mathrm{d}$ e a l Utte against AIDS. These marketing methods are based on communication and promotion strategies developed well and the willingness stock i rare well definies per putting stakeholders to sout e $\mathrm{n}$ ir public action to have sour $\mathrm{r}$ acceptance and hard Abilit ed of services VCT (MLS, 2005; Luwesi et al., 2018) [13-45].

\section{Conclusion}

AIDS, which is a pparue worm s the 1980 s, is so quickly become a pandemic and a real problem s Public ante development and economic and social. The fight against HIV is the 6 th Objectif for Development Durable (ODD) in the world. Thus in Africa and DRC, HIV infection / AIDS is still considered as the first concern of the manager 's questions san i t Air e s, because it is among other things a major cause of infant and child mortality e $\mathrm{n}$ RD C, where the HIV prevalence stood at at least $4.1 \%$ in 2007, in the general population, and in $90 \%$ in the child. Thus one can hardly expect an epidemiological situation of HIV / AIDS better in the area of Sant é Kenge, in 2018, rather than catastrophic, compared with the 'year 198 3, when the first AIDS cases are were notified.

Despite this very high number of people already living with HIV / SI DA, it is estimated that less than $10 \%$ s people in the world are aware of their status, even to post NACP (2009), VCT coverage on all of el extent of a DRC remains around $24.5 \%$, which corroborates the result of $22.7 \%$ found for years the five VDCs on a set of 23 health 
facilities that make up the area Kenge Health Center. The reason s advances are mainly related to deficiencies in the availability, access and attendance of council services and of voluntary HIV testing (VCT), and Kenge Health Zone is no exception to th this drama. Thus, the use of VCT services have it be at any cost encouraged. This is the epitome of not $r$ e study in Kenge health zone.

This study aimed to clarify some light on issues related to the proportion of people who have used VCT services in the health zone of Kenge e $t$ the factors having determined that head decision or justifying the favorable use VCT services. After collecting and analyzing the data, he results indiquent that the proportion of people who have used the VCT is higher than the national average in Kenge health zone. Moreover, He would exist the significant relationship $s$ between the use of $s$ VCT and some factors socio economics (marital status, the age, $\mathrm{t}$ go household, and has knowledge of e where s e finds the CDV).

\section{Recommendation}

As a recommendation, the authors of this article strongly challenge the Congolese government to be able to support the fight against HIV / AIDS in the Province Kwango in general and the city of Kenge in particular. By establishing communication channels officials clear e $t$ in promising VCT as behavior change promotion networks for years to the Utte against AIDS, the State will have sour $r$ acceptance and hard Ability of services VCT DRC in general and in particular Kwango. Moreover, the art outreach screening and the use of condoms, distribution of condoms and ARVs to health facilities and the management of patients in decision have as much support c es marketing methods and are precautionary measures to reduce the prevalence of HIV / AIDS and curb the scourge of this pandemic. But all these promotional strategies of knowledge so no status s e $r$ o logic and the willingness stock i $r$ es to lead must first be well defines and based on a communication e interactive to permeate stakeholders to sout in public action of VCT services.

\section{Webography}

a) World Health Organization (WHO): www.who.int

b) Program National LUtte against the S IDA (NACP): www. pnmls.cd

c) Program of Bank $M$ orld on the response and the epidemiology of HIV / AIDS: www.worldbank / aids....

\section{References}

1. (2008) WHO, World Organization of the Sant ed HIV / AIDS Program: F aits outstanding 2008-09? Geneva: Secretariat of the World Organization of the Sant é (WHO) Switzerland.

2. Karkouri M (2010) HIV counseling and testing in Southern countries. Casablanca Workshop 2010, Morocco.

3. (2009) MOH, Ministry of Sante PNLS, Standards and Guidelines for HIV Testing and Counseling. Wolters Kluwer, Wageningen, The Netherlands.

4. (2006) Sawadogo l perceptions, attitudes and practices of universities Burkina Faso are facing people living with HIV / AIDS. Memory of the Superior Deleplom of Health Attachés in Epidemiology. Ouagadougou: National School of Public Health (ENSP) Burkina Faso.
5. Bank M orld (2008) Synthesis of the response and epidemiology of HIV / AIDS in West Africa implications for prevention. Washington, DC: Group Bank M orld, USA.

6. Lowndes CM, Alary, Belleau M, Bosu WK, Kintin, DF, et al. (2008) Synthesis of the response and epidemiology of HIV / AIDS in West Africa. Implications for prevention. World Bank Global HIV / AIDS Program, Global Monitoring and Evaluation Team (GAMET) Washington, USA.

7. (2012) NFETAM State of play of the fight against HIV in Cameroon. Yaoundé: NFETAM, Cameroon Republic.

8. (2009) MINISANTE, Ministry of Health National Strategic Plan to fight AIDS, 2010 - 2014. Kinshasa Republic Démocratique of Congo.

9. (2017) City of Kenge Administrative Census 2017. Kenge: Town Hall of Kenge City, Kwango Province, Democratic Republic of Congo.

10. Hargreaves (2008) HIV infection in sub-Saharan Africa. AIDS 3022 (3): 403- 414.

11. Baggaley RF, White RG, Boily MC (2008) Systematic review of urogenital HIV-1 transmission probabilities. International Journal of Epidemiology 37 (6): 1255-65.

12. Ouedraogo TL (2001) HIV infection and changing social relations: a study of 188 HIV-infected people in Ouagadougou. C antery S ante $\mathrm{N}^{\circ} 4$ (Ouagadougou, Burkina Faso).

13. Luwesi CN, Nutsukpui AA, Wambua PP, Nkpeebo AY (2018) Societal marketing and resource mobilization: Communication and engagement methods that work for water. In: A. Beyene, and CN Luwesi (eds.) Innovative Water Finance in Africa - A Guide for Water Managers Vol ume 1: Water Finance Innovations in Context. Uppsala: Nordiska Afrikainstitutet, Sweden, pp. 114-139.

14. (2005). MLS, Ministry of the Fight against AIDS National Communication Strategy for Change in Behavior in the Face of HIV / AIDS. Abidjan: Republic of Ivory Coast.

15.Amuli J (2013) Scientific Research Methodology in Healthcare and Health, from conception to diffusion. Media Paul, Kinshasa, RD Congo.

16. Bouchaud O (2011) Comprehensive HIV Care in Resource-limited Settings - A Training Guide for Paramedics. Editions Doin, Paris, France.

17. Courpotin C (2013) natural history of HIV infection in children. Paris, France.

18. (2018) DPS/Kwango Projection s ani ta i re 201 8. Kenge: Directorate Provincial d u K wa ng o, Kwango Province, Democratic Republic of Congo.

19. Fainzang S (2003) Medicines in the private area: individual or collective management. Anthropology and Societies 27 (2): 139-154.

20. Fainzang S (2006) What are the prescribed medications? Info Respiration, $\mathrm{N}^{\circ} 74: 23-24$.

21. Fassin D (1992) Power and disease in Africa, Paris, Presses Universitaires de France.

22. Jaffre Y, Olivier de Sardan, JP (2000) An inhospitable medicine. Difficult relations between caregivers and care in five capitals of West Africa, Paris: Karthala.

23. Loukid M (2014) Q uestion of HIV status sharing among people living with HIV in Morocco. Casablanca: Kingdom of Morocco.

24. M Akano A (2007) Getting person dependents living with HIV / AIDS da $n$ $\mathrm{s}$ the city of Butembo. M emory of L icencie in Gender and Development. F aculty of Social Sciences - Political Labrador administrative, official University of Ruwenzori, Butembo, Republic Démocratique of Congo. MSF, Doctors S years Frontières (2008) Accompanying the child patient infected with HIV. Paris, Médecins S ans Frontieres (MSF) French Republic.

25. (2010) MINISANTE, Ministry of Health PNLS, guide for the management of HIV infection in children in DR Congo. Kinshasa Republic Démocratique of Congo. 
26. (2004) MOH, Ministry of S ante PNLS, standards and guidelines for voluntary testing for HIV / AIDS. Kinshasa Republic Démocratique of Congo.

27. (2011) MOH, Ministry of S ante PNLS, national guide of clinical tutoring on HIV / AIDS care in the DRC. Kinshasa Republic Démocratique of Congo.

28. (2011) MOH, Ministry of S ante PNLS: Integrated Module of Providers in HIV / AIDS. Kinshasa Republic Démocratique of Congo.

29. (2011) MINISANTE, Ministry of Health Annual report of the PNLS 2011. Kinshasa: P rogram N ational L Utte against the S IDA (NACP) Republic Démocratique of Congo.

30. MOH, Ministry of S ante (2012) HIV profile. Kinshasa: Program National Utte against the SIDA (NACP) Republic Démocratique of Congo.

31. (2015) MOH, Ministry of S ante CNLS - Progress Report on AIDS and Report on Progress Towards Universal Access. Bujumbura: Council N ational L Utte against the S IDA (C NLS) Republic of Burundi.

32. Moha, M (2011) Even the food, you get tired of eating it. PLHIV and drugs in Niger. Niamey, Studies and Works No. 94.

33. Niele T (2013) Qualitative study of decision-making of women living with HIV about the unveiling or not their status in Bamako, $\mathrm{F}$ aculty M edical and Dentistry. Doctoral thesis. Bamako: University of Science, Technology and Technology of Bamako (USTTB) Republic of Mali.

34. (2010) WHO, World Health Organization The e HIV and AIDS? Recommendation $N^{\circ} 200$ (WHO, Geneva, Switzerland).

35. (2009) UNAIDS, Program of N United ations for L Utte against the SIDA Fight stigma and HIV-related discrimination-an essential element of national AIDS programs. Geneva: World Organization Secretariat of Health ed (WHO) Switzerland.

36. (2003) UNAIDS Report on the global HIV / AIDS epidemic. Geneva: World Organization Secretariat of Health ed (WHO) Switzerland.

\section{ISSN: 2574-1241}

DOI: 10.26717/BJSTR.2019.18.003172

Cush Ngonzo Luwesi. Biomed J Sci \& Tech Res

(C) This work is licensed under Creative

Commons Attribution 4.0 License

Submission Link: https://biomedres.us/submit-manuscript.php
37. (2006) UNAIDS Report on the global AIDS epidemic. Geneva: World Organization Secretariat of Health ed (WHO) Switzerland.

38. (2002) UNDP, United Nations Development Program L e HIV / AIDS and Strategies of reducing poverty. Washington, DC: Secretariat of the United Nations Development Program (UNDP) USA.

39. (2008) UNDP, United Nations Development Program Mobilization of people infected and affected by HIV / S IDA in Kisangani and Kinshasa. Communication present ed th at the workshop of the PVV. Ki n s h has its: UNDP RD- C, Republic Démocratique of Congo.

40. (2013) UNDP, United Nations Development Program Report of the evaluation of the community HIV prevention project in $\mathrm{W}$ alungu center Walikale: DR Congo.

41. (2009) UNDP United Nations Development Program Integrate gender into national HIV / AIDS strategies and plans. Kinsh has its: UNDP RD- C, Republic Démocratique of Congo.

42. Sawadogo (2007) Factors limiting the use of voluntary counseling testing (VCT) of HIV by people aged 15-49 the health district of Kaya. Memory of the Superior Deleplom of Health Attachés in Epidemiology. Ouagadougou: National School of Public Health (ENSP) Burkina Faso.

43. Tulizana (2010) Factors favoring the use of the activities of a voluntary counseling and testing center in the city of Bukavu. Specific case of the counseling and testing center of the FARDC hospital center. Memory Licence public health. Bukavu: ISTM of Bukavu, Democratic Republic of Congo.

44.Zigani (2004) Studies of factors limiting the low use of voluntary counseling services by persons practicing in the informal sector in the city of Ouaga dougou - There are small traders. Diploma of Higher Technician Diploma in Nursing and Midwifery. Ouaga dougou: National School of Public Health (CFDS) Burkina Faso.

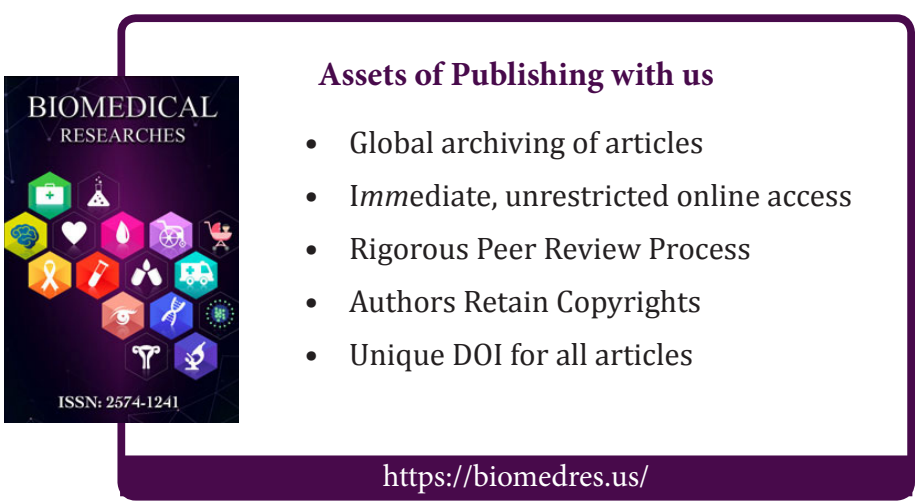

